\section{Review Article}

General Laboratory Medicine

(D)

Ann Lab Med 2019;39:121-124

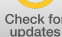

https://doi.org/10.3343/alm.2019.39.2.121

ISSN 2234-3806 elSSN 2234-3814
ANNALS OF

LABORATORY

MEDICINE

\title{
Reducing Diagnostic Errors Worldwide Through Diagnostic Management Teams
}

\author{
Roberto Verna $\mathbb{C}^{0}$, M.D., Ph.D. ${ }^{1,2}$, Adriana Berumen Velazquez, Ph.D. ${ }^{3}$, and Michael Laposata, M.D., Ph.D. ${ }^{4}$ \\ ${ }^{1}$ World Association of Societies of Pathology and Laboratory Medicine, ${ }^{2}$ Department of Experimental Medicine, Sapienza - University of Rome, Italy; \\ ${ }^{3}$ Innovation Access and Use, Medicines and Health Products Department, World Health Organization, Geneva, Switzerland; ${ }^{4}$ Department of Pathology, \\ University of Texas Medical Branch, Galveston, USA
}

A major challenge facing most countries is the growing cost of healthcare. Laboratory testing costs constitute approximately $3 \%$ of all clinical costs, while waste of funds due to inappropriate admissions to clinical departments is reported to be as high as 15\%. A frequently used approach to save money in healthcare is random reduction of laboratory budgets, focusing on decreasing the number of unnecessary laboratory tests. The World Health Assembly has approached this problem by publishing a list of essential in vitro diagnostic tests, to achieve a global rationalization of the problem. A much more thoughtful strategy to reducing healthcare expenditure is to improve the efficiency of the diagnostic process. Decreasing the time to a correct diagnosis provides considerable financial and clinical benefits. Additionally, reducing both overutilization and underutilization of laboratory tests while achieving the correct diagnosis is of great benefit to challenged healthcare budgets. Examining the situation in the United States and Italy, this review presents an opportunity for reducing diagnostic error and increasing the efficiency of diagnostic testing worldwide. One approach taken to achieve major savings in healthcare in the United States, which can be applied in Italy and other countries, is the creation of "diagnostic management teams," comprising experts in specialty areas of medicine, primarily based in the clinical laboratory, who can advise physicians on the selection of necessary tests and the interpretation of complex test results.

Key Words: Diagnosis, Diagnostic error, Clinical laboratory, Diagnostic management team

\author{
Received: June 28, 2018 \\ Revision received: July 26, 2018 \\ Accepted: September 27, 2018
}

Corresponding author: Roberto Verna, M.D. (iD) https://orcid.org/0000-0002-1869-3912 Department of Experimental Medicine, Sapienza - University of Rome, Viale

Regina Elena 324, 00161 Rome, Italy Tel: +3939 24681165

E-mail: roberto.verna@uniroma1.it

\begin{abstract}
(c) Korean Society for Laboratory Medicine This is an Open Access article distributed under the terms of the Creative Commons Attribution Non-Commercial License (http://creativecommons.org/licenses/by-nc/4.0) which permits unrestricted non-commercial use, distribution, and reproduction in any medium, provided the original work is properly cited.
\end{abstract}

\section{INTRODUCTION}

There is continuous discussion at the World Health Assembly regarding the use of financial resources to promote health and well-being [1]. The first essential in vitro diagnostics list was released by the World Health Organization in May 2017, in recognition of the importance of diagnosis prior to treatment. It includes $>100$ tests and will be expanded every year to guide countries regarding appropriate test selection [2, 3].

Despite the large number of deaths due to diagnostic errors, there is still limited awareness of the possibility of reducing mortality and morbidity by investing in improving diagnostic accu- racy and speed [4]. Seventy to eighty percent of the information in medical records consists of laboratory data [5]. The likelihood that a diagnosis is established using information from one or more of the associated diagnostic areas of anatomic pathology and radiology is extremely high in industrialized countries, where such information is readily available [4].

The growth of genetic testing has enabled the identification of disorders that were previously either undiagnosed or misdiagnosed and therefore not effectively treated. The area of genetic testing that permits identification of effective drugs, known as pharmacogenomics, is dramatically expanding. Treatment with the correct drug at the right time often depends on the perfor- 
mance of initial genetic laboratory tests; however, recognition of the possibility of more effective drug therapy using laboratory testing is still quite limited across the globe [6].

Alongside improvements in clinical outcomes that could be realized by modest investments in the diagnostic process, tremendous financial benefits could be gained from rapidly achieving an accurate diagnosis. The reduction in expenditures resulting from shortened time to effective treatment and shortened length of stay for hospitalized patients far exceeds the money spent on testing, regardless of how healthcare is paid for in different countries. Disease complications and the requirement to treat advanced diseases rather than early-stage diseases are both extremely expensive $[4,7,8]$. The response of many hospital leaders, particularly those lacking clinical experience, is to invoke universal reductions and expenditures, without the understanding that a missed or delayed diagnosis is associated with losses in other budgets outside the diagnostic specialties [8].

Importantly, the citizens of most countries are largely unaware that poor clinical outcomes could be prevented if the diagnostic processes were improved. Healthcare providers in many countries can lose patients, and therefore income, if they reveal to their patients that they were responsible for a diagnostic error. Procedural errors, such as removing the wrong kidney in case of a renal carcinoma or treatment with the wrong drug dose, are easily recognizable causes of mortality and morbidity; however, it is far more difficult to estimate the effect of the greater number of errors related to establishing a diagnosis [8]. While much attention has been paid to improving processes to reduce procedural errors, there is limited, if any, effort in most countries to increase the awareness of institutions and individual healthcare providers regarding the diagnostic errors they have made and the poor outcomes that are attributable to their incorrect selection of diagnostic tests or their failure to correctly interpret the diagnostic test results $[8,9]$.

\section{DIAGNOSTIC ERRORS IN THE UNITED STATES}

In the United States, there are many causes for diagnostic errors during the diagnosis and treatment of patients [10]. The abundance of lawsuits for medical errors prompts healthcare providers to take a defensive position, which leads to unnecessary "defensive" testing. The lack of attention to laboratory medicine in medical school and by those in practice produces $>10,000$ new physicians in the United States who "do not know what they do not know" [8, 10]. The disparity between substantial payment for diagnoses using anatomic pathology and radiology and scant payment for establishing a diagnosis via laboratory medicine has resulted in a situation where there are very few experts who are able to help clinicians order the correct laboratory tests and correctly interpret the results (Fig. 1). A recent report identified the barriers impeding widespread use of expert consultation services through a diagnostic management team in the United States [10]. These include low payment for personalized and expert-driven narrative interpretations in clinical pathology, the demand for laboratory directors with an M.D., the high number of lawsuits for medical errors, the intense competition among healthcare systems, a frequent adversarial relationship between administrative and physician leaders and hospitals, the failure of non-physician leaders to understand the details of the diagnostic process, the demand to quantify savings from diagnoses that are rendered more accurately and more quickly because of expert diagnostic input even though the savings are difficult to quantify and are often realized outside the laboratory, and the lack of clinical pathology coursework in American medical schools [11].

\section{DIAGNOSTIC ERRORS IN ITALY}

Currently, the Italian Government is conducting a review of its healthcare spending. Many of these reductions in expenditures

The most common diagnosis process worldwide and how it leads to diagnostic errors

The patient presents to a local physician.

The local physician attempts to perform diagnostic tests that potentially identify disease $X$

If the physician has seen only a few cases of disease $X$, consultation with a nearby physician who has seen (perhaps only a few) more cases of disease $X$ may be requested.

An expert with current knowledge regarding disease $X$, who is not local but easily contactable, who knows how to identify disease $X$ rapidly with the appropriate diagnostic tests and no unnecessary tests, is virtually never consulted because the expert is not local.

Diagnostic error is much more likely to occur because the local doctor has limited experience with disease $\mathrm{X}$.

Patient diagnosis is delayed, the patient is misdiagnosed, the patient is treated with an ineffective therapy, or the diagnosis is achieved but with many unnecessary tests.

The patient has no knowledge that the local doctor is not an expert and that a true expert who is easily contactable was not involved in his or her care.

Fig. 1. Current primary care doctor and consultant roles in making a diagnosis. 
include activities in the clinical laboratory, and the steps being taken are compromising diagnostic speed and accuracy. In Italy, as in other countries, improvement in diagnostic services that cost little can save thousands to millions of euros. For example, the clinical center in Rome for patients with thalassemia and other anemias was recently closed, even though thalassemia accounted for $14-15 \%$ of the anemia cases in an almost exclusively Italian elderly population [12]. The proposed savings from this closure (approximately ten million euro annually) are likely to be offset by the much larger healthcare costs for this patient population; patients are now less likely to be identified and, even if identified, less likely receive the correct treatment. It is impossible to calculate the costs of these losses in terms of diagnostic and treatment support for these patients. Although Italy may have different obstacles hindering the rapid establishment of accurate diagnosis compared with the United States, the number of obstacles is still substantial enough to require major infrastructure improvements in the country's healthcare delivery system. The obstacles to diagnostic management team implementation are more similar than different in the United States and Italy. In Italy, there is also little incentive, financial or otherwise, to perform the considerable extra work to investigate the clinical record and create a patient-specific, expert-driven narrative interpretation of clinical laboratory results.

\section{IMPROVING DIAGNOSTIC SPEED AND ACCURACY IN BOTH COUNTRIES}

Over the past 20 years in the United States, but most prominently in the past few years, diagnostic experts have been teaming up to support clinical colleagues who are in direct contact with patients. These teams, known as diagnostic management teams, provide advice on laboratory test selection and test result interpretation [13-15]; they have updated information regarding diagnoses in specialized areas, for example, bleeding and clotting disorders. When experts, situated either locally or remotely from the healthcare provider, can provide information while clinical decisions are being made, the likelihood of an efficient diagnostic process is substantially increased. Communication between the diagnostic management team and the treating healthcare provider is becoming simpler, and it now allows for backand-forth questioning until a diagnosis is achieved. Once the diagnosis is established, the patient is ready for treatment, and the most up-to-date information from those who read the latest journals in their specialty is now available. Diagnostic management teams have been created and successfully implemented in many areas, including coagulation, leukemia and lymphoma, transfusion medicine, microbiology/infectious disease, and even the review of presumed child abuse cases for the presence of an underlying bleeding disorder.

The coagulation diagnostic management team at Vanderbilt University in Nashville, TN, USA, was able to dramatically decrease the length of stay, from a national average of 4 days to 2 days, and the cost of care for patients with pulmonary embolisms and intracranial hemorrhages [16]. The diagnostic management team for patients with leukemia and lymphoma at that same institution has improved the diagnostic speed and accuracy of hematologic malignancies [13]. The average cost for each bone marrow in the six months preceding implementation was USD 2,390. The corresponding cost one year later was USD 1,948 , a difference of USD 442 per case. Based on an annual institutional volume of approximately 1,800 adult bone marrow specimens, this represented yearly savings to payers of USD 522,000-USD 1,069,200.

There is currently global interest in the creation of diagnostic management teams. Conferences focusing on the creation of diagnostic management teams have been held in Galveston, TX, USA, in 2017 and 2018 [17], and the information from these meetings has spread globally. Healthcare delivery and payment for healthcare varies significantly across countries. However, a constant finding in all countries, both industrialized and non-industrialized, is the abundance of obstacles impeding the establishment of rapid and accurate diagnosis. The specific obstacles may differ among countries, but they are numerous. As described above, the implementation of diagnostic management teams across the globe could eliminate many of the obstacles to achievement of rapid and correct diagnosis.

\section{CONCLUSIONS}

There is a great need for communication between healthcare providers in direct contact with patients and expert diagnosticians; this need continues to grow as clinical records of patients now contain an increasing amount of complex genetic results. The challenges in reaching an accurate and rapid diagnosis are exemplified by the situations in the United States and Italy, which most likely reflect a global need as diagnostic information becomes more abundant and more expensive.

\section{Authors' Disclosures of Potential Conflicts of Interest}

No potential conflicts of interest relevant to this article are reported. 


\section{Acknowledgements}

The authors would like to thank Ms. Sherrill Hebert for assistance in preparation of the manuscript.

\section{REFERENCES}

1. Essue BM, Laba M, et al. Economic burden of chronic ill health and injuries for households in low- and middle-income countries. In: Jamison DT, Gelband H, et al., eds. Disease control priorities: improving health and reducing poverty. 3rd ed. Washington (DC): The International Bank for Reconstruction and Development/The World Bank, 2017:121-46.

2. World Health Organization. World Health Organization model list of essential in vitro diagnostics. 1st ed. http://www.who.int/medical_devices/ diagnostics/WHO_EDL_2018.pdf (Updated on Jun 2018).

3. World Health Organization. Selection, access and use of in vitro diagnostics. http://www.who.int/medical_devices/diagnostics/Selection_in-vitro_diagnostics/en/ (Updated on Jun 2018).

4. Institute of Medicine (US) Committee on Quality of Health Care in America, Kohn LT, et al. eds. To err is human: building a safer health system. Washington, DC: The National Academies Press, 2000:1-312.

5. Hallworth MJ. The "70\% claim": what is the evidence? Ann Clin Biochem 2011;48:487-8.

6. Daly AK. Pharmacogenetics: a general review on progress to date. $\mathrm{Br}$ Med Bull 2017;124:65-79.

7. Hickner J, Thompson PJ, Wilkinson T, Epner P, Sheehan M, Pollock AM, et al. Primary care physicians' challenges in ordering clinical laboratory tests and interpreting results. J Am Board Fam Med 2014;27: 268-74.
8. Committee on Diagnostic Error in Healthcare, Board on Health Care Services, et al. eds. Improving diagnosis in health care. Washington, DC: National Academies Press, 2015;1-472.

9. Bindraban RS, Ten Berg MJ, Naaktgeboren CA, Kramer MHH, Van Solinge WW, Nanayakkara PWB. Reducing test utilization in hospital settings: a narrative review. Ann Lab Med 2018;38:402-12.

10. Laposata M. Obtaining a correct diagnosis rapidly in the United States is associated with many barriers not present in other countries. Am J Clin Pathol 2018;149:458-60.

11. Smith BR, Kamoun M, Hickner J. Laboratory medicine education at U.S. medical schools: a 2014 status report. Acad Med 2016;91:107-12.

12. Tettamanti M, Lucca U, Gandini F, Recchia A, Mosconi P, Apolone G, et al. Prevalence, incidence, and types of mild anemia in the elderly: The "Health and Anemia" population-based study. Haematologica 2010; 95:1849-56.

13. Seegmiller AC, Kim AS, Mosse CA, Levy MA, Thompson MA, Jagasia $\mathrm{MH}$, et al. Optimizing personalized bone marrow testing using an evidence-based, interdisciplinary team approach. Am J Clin Pathol 2013; 140:643-50.

14. Laposata M and Dighe A. "Pre-pre" and "post-post" analytic error: highincidence patient safety hazards involving the clinical laboratory. Clin Chem Lab Med 2007;45:712-9.

15. Laposata ME, Laposata M, Van Cott EM, Buchner DS, Kashalo MS, Dighe AS. Physician survey of a laboratory medicine interpretive service and evaluation of the influence of interpretations on laboratory test ordering. Arch Pathol Lab Med 2004;128:1424-7.

16. Aquino AC. How to spot the savings from a diagnostic management team. CAP Today 2017;Oct. Online version available at http://captodayonline.com/spot-savings-diagnostic-team/.

17. University of Texas Medical Branch, DMTConference.com 2017 and 2018. https://www.dmtconference.com/ 